\title{
Adherence to Cholinesterase Inhibitors in Alzheimer's Disease: A Review
}

\author{
Roseanna Brady ${ }^{a}$ John Weinman ${ }^{b}$ \\ ${ }^{\mathrm{a}}$ Atlantis Healthcare and ${ }^{\mathrm{b}}$ Institute of Psychiatry, Kings College London, London, UK
}

\section{Key Words}

Alzheimer's disease $\cdot$ Medication adherence $\cdot$ Medication persistence $\cdot$ Medication non-adherence

\begin{abstract}
Background/Aims: Treatment adherence is a major problem in numerous medical conditions, and is a particular challenge in patients with Alzheimer's disease (AD). Methods: This non-systematic review summarises the current literature on factors that affect adherence to cholinesterase inhibitors, the mainstay of AD treatment. Articles listed on PubMed and published during the last 10 years were included. Results: Intentional factors affecting adherence include patient, caregiver and prescriber beliefs about therapies and the disease itself. Unintentional factors include tolerability, physical limitations of the patient and caregiver burden. Interventions aiming to improve adherence include educational programmes and new drug delivery methods. Conclusion: Due to the high level of caregiver involvement in the care of patients with $A D$, strategies that address caregiver concerns may improve adherence.
\end{abstract}

Copyright $(2013$ S. Karger AG, Basel

\section{Introduction}

The effectiveness of any treatment is dependent upon the required medications being administered as prescribed. However, treatment adherence (or compliance), defined as 'the extent to which a patient's behaviour matches agreed recommendations from the prescriber' [1], is a major problem in the management of many medical conditions $[1,2]$.

Alzheimer's disease (AD) is the most common cause of dementia worldwide, with global prevalence estimated to be as high as 24 million, and predicted to double every 20 years through to $2040[3,4]$. AD is a chronic neurodegenerative condition characterised by a progressive deterioration of cognitive function [3, 4]. From onset, AD causes progressive deficits in memory, language, judgement, decision making, orientation and learning $[3,4]$. 
The mainstays of treatment for the relief of mild-to-moderate AD symptoms are the cholinesterase inhibitors (ChEIs) donepezil, galantamine and rivastigmine [5, 6]. Sustained use of these agents for 3 or more months may delay the worsening of cognitive, functional and behavioural symptoms of $\mathrm{AD}[5,7]$. However, treatment management is a major challenge in $\mathrm{AD}$, with non-adherence to treatment often a barrier to effective therapy $[8,9]$.

The aim of this non-systematic literature review is to highlight some of the challenges associated with adherence to ChEIs, since these are by far the most commonly prescribed medications for patients with $\mathrm{AD}$, and to discuss strategies addressing these issues in clinical practice.

\section{Methods}

A search of the online PubMed literature database (http://www.ncbi.nlm.nih.gov/pubmed) was performed in December 2011 using combinations of the following terms: Alzheimer's disease; cholinesterase inhibitors; adherence; compliance; persistence; caregiver, and non-adherence. In order to focus the search on up-to-date information, articles were limited to those published in the last 10 years. Only articles published in the English language were included. The search results were then manually assessed for relevance using the titles and abstracts of the publications. Further relevant references were selected from the bibliographies of identified papers. A summary of the key studies can be found in table 1.

\section{Treatment of AD Symptoms}

ChEIs cannot reverse AD or prevent its natural progression, instead they provide relief from symptoms $[5,10]$. With all three approved agents (donepezil, galantamine and rivastigmine), modest improvements in measures of disease severity last for approximately 6 months, but seldom result in recovery of lost function [5, 7]. Rigorous reviews of clinical trial data for each of the three available oral ChEIs show that they all reduce the rate of cognitive function decline and dementia severity, and improve performance in activities of daily living in people with mild-to-moderate AD [10-12]. However, functional capacities lost (e.g. the ability to manage finances or drive) are rarely recovered [5, 7, 10-12]. Owing to its dual action on both acetylcholinesterase and butyrylcholinesterase, it has been suggested that rivastigmine may also reduce behavioural symptoms in mild-to-moderate AD (galantamine and donepezil act solely on acetylcholinesterase) [13].

\section{Treatment Adherence in AD}

The Importance of Treatment Adherence in $A D$

$\mathrm{AD}$ has a major impact on the quality of life (QoL) of both the patient and the caregiver [14-16]. Given the short life expectancy following a diagnosis of AD (median 3-8 years [17]), and the progressive nature of the disease, treatments that stabilise symptoms or delay their progression, even for 6-12 months, can have important benefits on QoL for patients and their caregivers $[14,15]$. An observational study of 445 patients with $\mathrm{AD}$ found that the use of ChEIs for at least 1 year was associated with a decreased risk of rapid cognitive deterioration and institutionalisation [18]. It follows that patients who manage to adhere to AD therapies for longer have a greater chance of slowing or delaying progression of their symptoms and increasing their QoL [8]. Furthermore, a delay in institutionalisation of patients may also lead to savings in healthcare costs $[19,20]$. 
Dementia

and Geriatric
Cognitive Disorders
Dement Geriatr Cogn Disord 2013;35:351-363

DOI: 10.1159/000347140

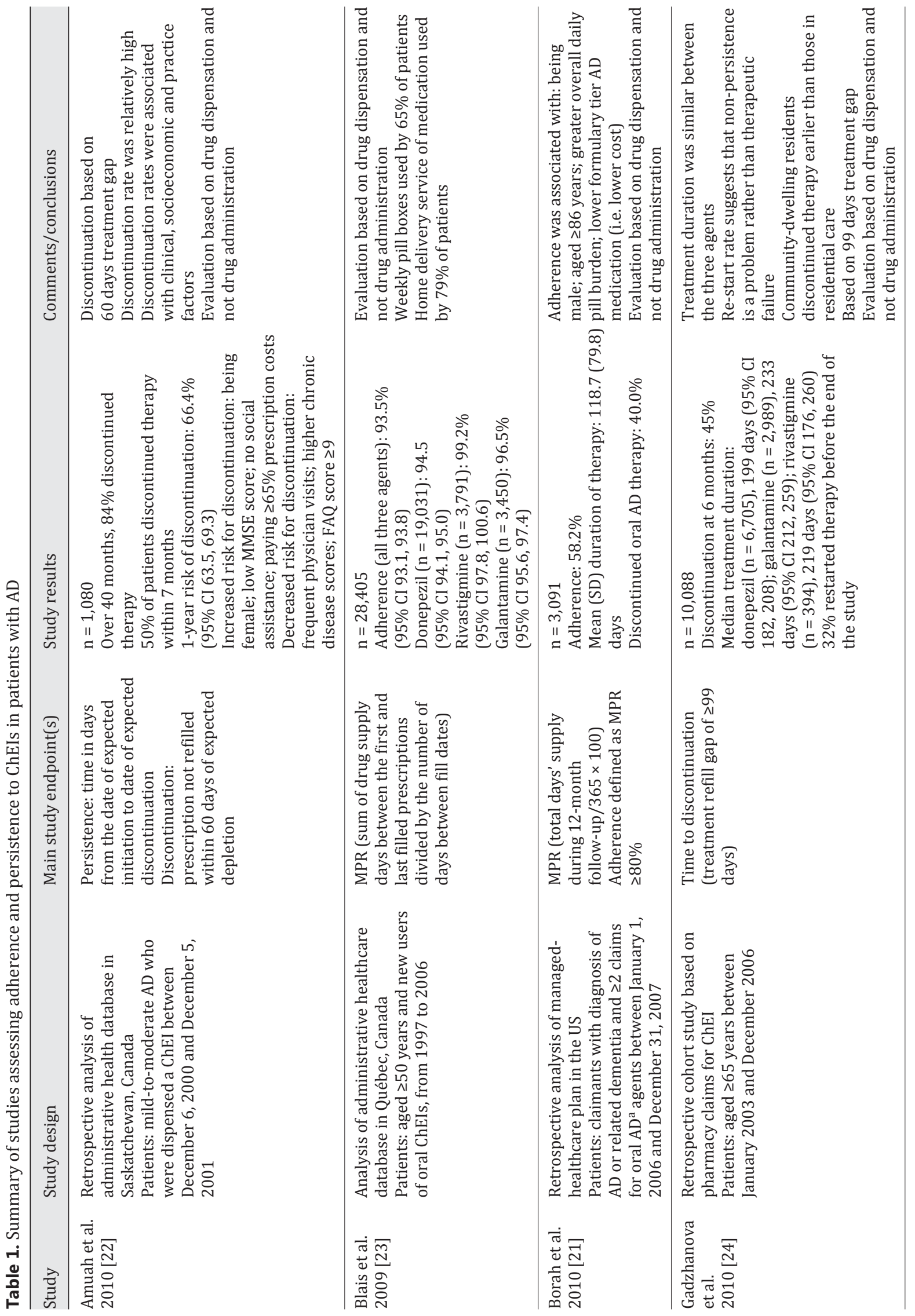


Dementia

Cognitive Disorders
Dement Geriatr Cogn Disord 2013;35:351-363

DOI: $10.1159 / 000347140$

Brady et al.: Adherence to Cholinesterase Inhibitors in Alzheimer's Disease: A Review

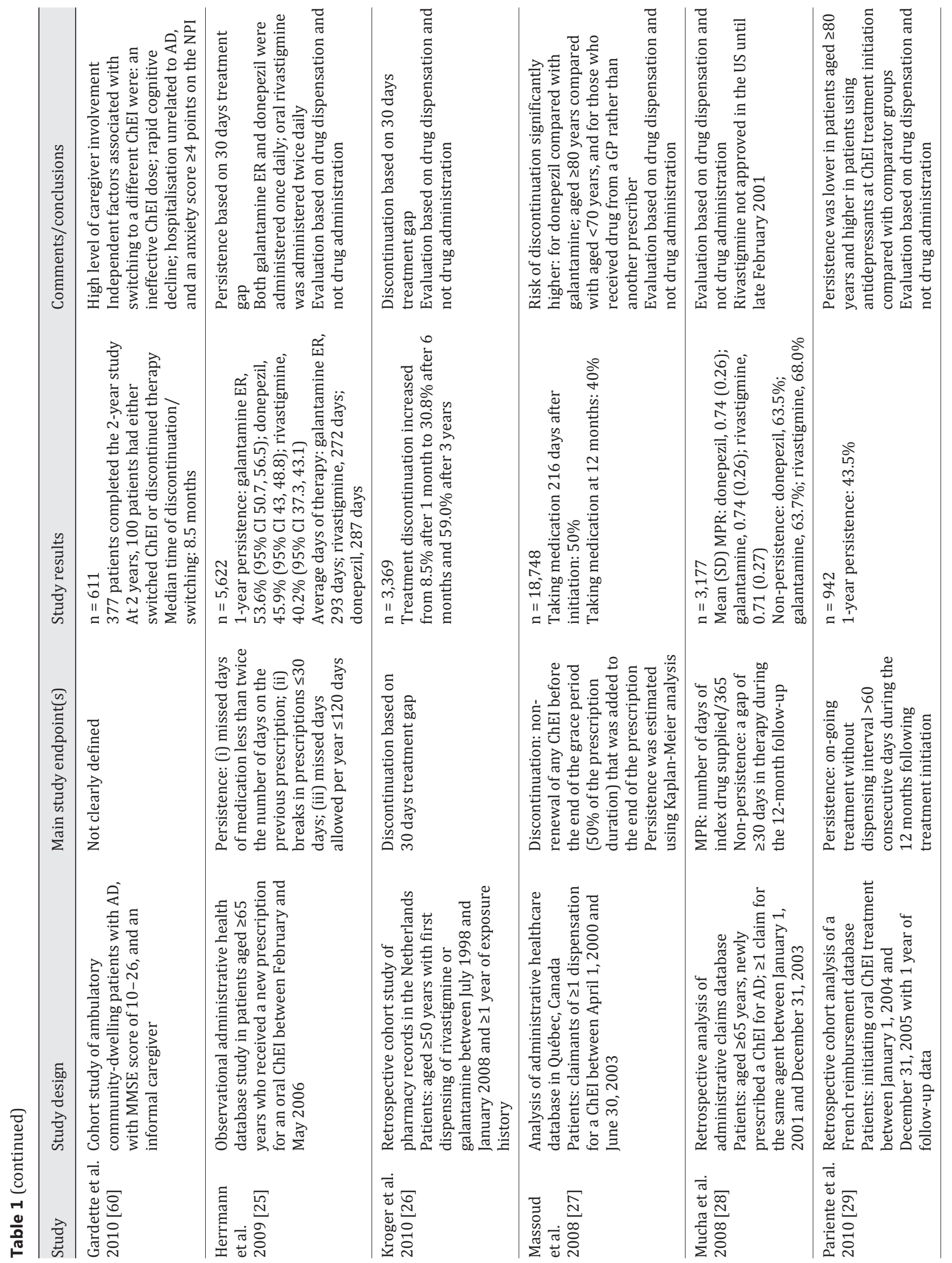




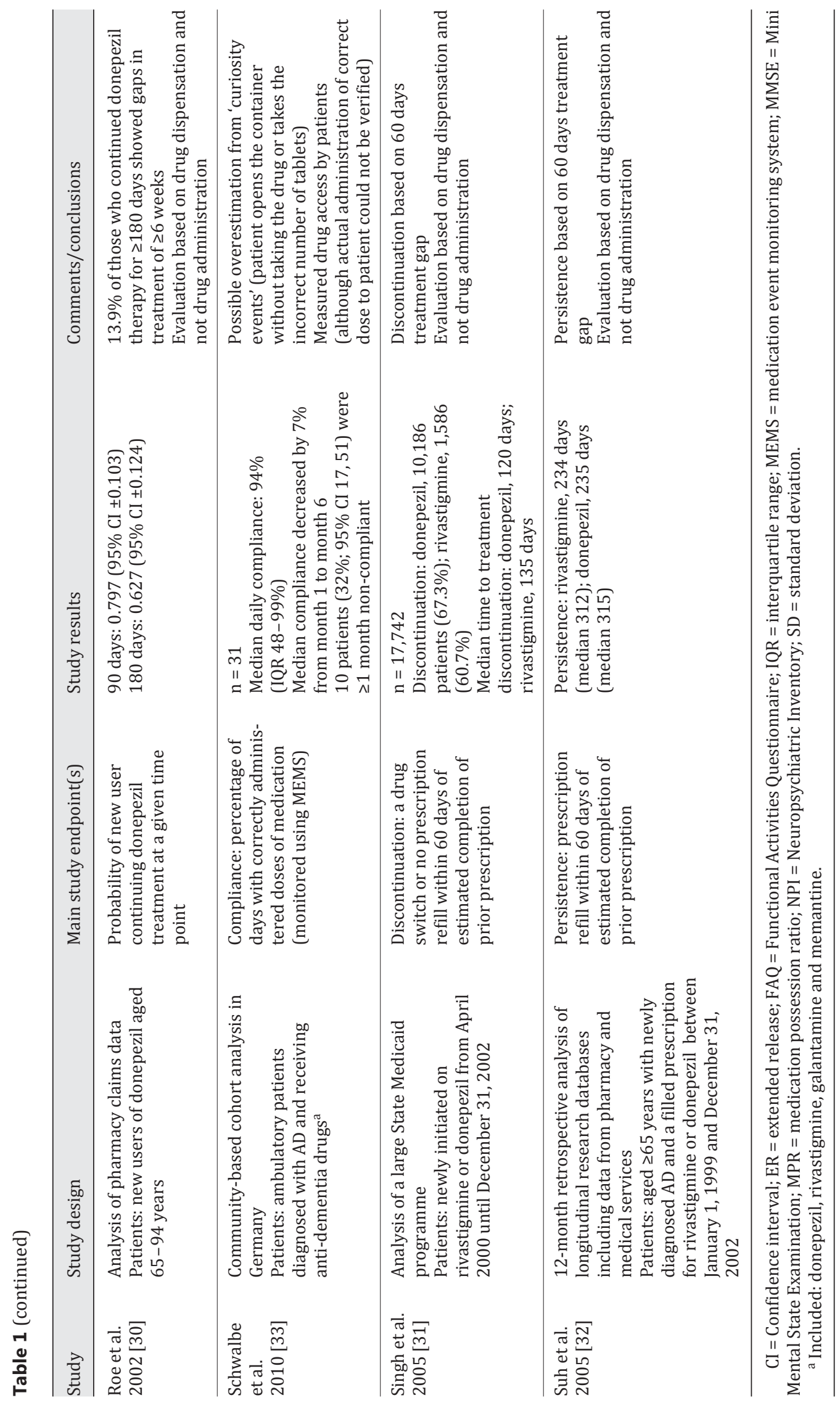




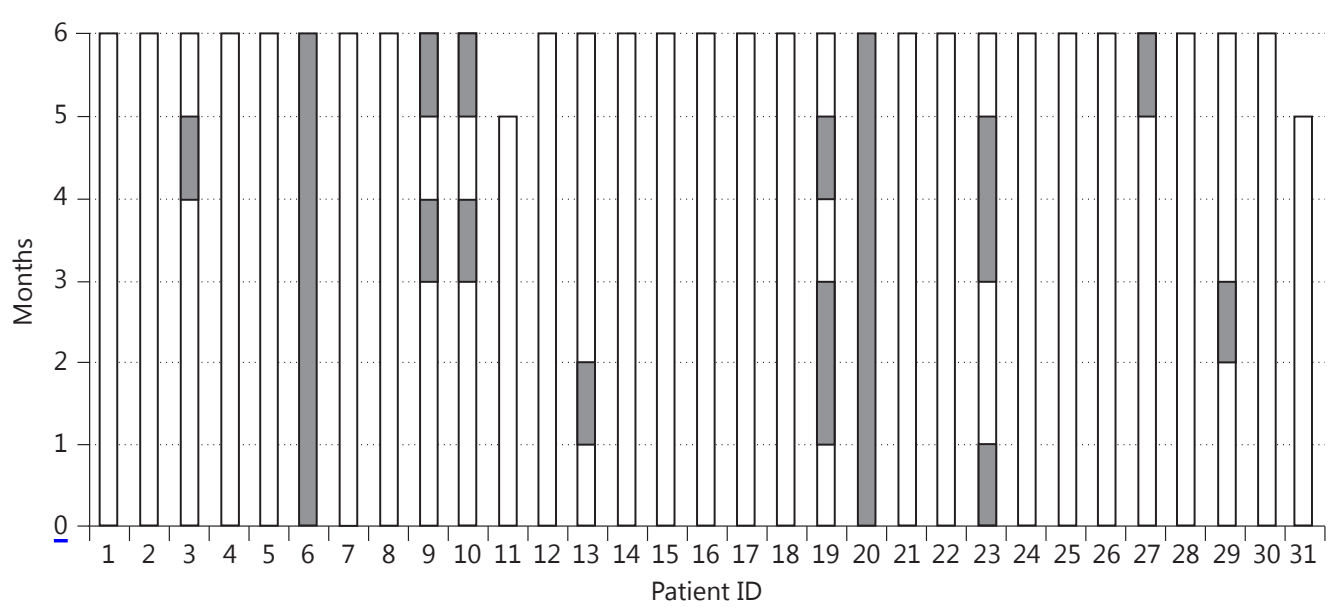

Fig. 1. An example of intra-individual differences in adherence to treatment in patients with AD (reproduced with permission from Schwalbe et al. [33]). Compliance was assessed over 6 months in a cohort of ambulatory patients with AD ( $\mathrm{n}=31)$ using an electronic Medication Events Monitoring System (MEMS). The MEMS device consisted of a vial with a microprocessor in the lid which recorded the time (date, hour and minute) of every opening. Daily compliance served as primary outcome measure and was defined as the percentage of days with correctly administered doses of medication. The graph shows compliant months (daily compliance $\geq 80 \%$, white bars) and non-compliant months (daily compliance $<80 \%$, grey bars) for all 31 patients. Patients 11 and 31 participated in the study for 5 months only.

\section{Studies Investigating Treatment Adherence in AD}

Published data on treatment adherence and persistence (the length of time from initiation to discontinuation of treatment) in $\mathrm{AD}$ reveal conflicting results. In part, this may be owing to different methodological processes, such as the length of time taken to signify treatment discontinuation (e.g. 30, 60 or 90 days between prescription refills) or the environmental settings in which adherence has been studied (table 1). Many studies investigating treatment adherence or persistence in patients with AD have been performed using retrospective analyses of administrative health databases or pharmacy claims [21-32]. It should be noted that in all of these studies, evaluation of adherence is based on drug dispensation and not actual drug intake by the patient.

In one retrospective analysis of a managed healthcare plan in the US between 2006 and 2008 , only $58.2 \%$ of the 3,091 patients with AD identified were adherent to oral AD medications (including all three ChEIs or the N-methyl-D-aspartate antagonist, memantine, which is indicated for use in moderate-to-severe AD) over the 12-month follow-up period [21]. In this study, a number of variables were associated with better adherence to oral AD medication, including being male, age $\geq 86$ years, and using a lower formulary tier AD medication [21]. Unfortunately, the database had no information on caregiver support, medication management interventions, or use of adherence aids that may have affected adherence in this cohort. Conversely, in a retrospective community-based survey of dispensing records performed over a 9-year period in Canada, 93.5\% adherence to ChEIs was observed [23]. However, as mentioned previously, treatment adherence was measured based on drug dispensation rather than the amount of drug actually administered to the patient, and in addition, home delivery was the most frequent way to dispense treatments, making adherence to treatment easier and more convenient for the caregiver. This may have led to an overestimation of actual adherence to treatment. 
In a recent study aimed at assessing actual medication administration/intake, adherence over a period of 6 months was assessed in a small cohort $(n=31)$ of ambulatory patients with $\mathrm{AD}$ using electronic monitoring (a medication vial with a microprocessor in the lid recording the time of every opening) [33]. On average, median compliance to ChEIs was $94 \%$ (range $49-99 \%)$ but was variable between patients, with 10 patients (32\%) $<80 \%$ compliant for a period of at least 1 month out of the 6 months studied (fig. 1) [33]. This study highlights that adherence rates may differ significantly between individual patients with AD.

Persistence is reported to be a particular problem in $\mathrm{AD}$ [8], perhaps more so than is adherence. Indeed, two treatment reviews performed in Canada assessing oral ChEIs showed that only $40-54 \%$ of patients achieved persistence at 12 months after initiation of therapy $[25,27]$. Additionally, in a French study, 1 -year persistence of ChEI treatment was estimated at $45.3 \%$ of 942 patients. The authors concluded that to optimise persistence with ChEIs, patients presenting with more severe symptoms and/or those aged over 80 years should be especially monitored [29].

In summary, evidence reported in the literature to date indicates that although day-today adherence to ChEIs can sometimes be high, there is a great deal of intra-individual and inter-study variation. In addition, persistence with medications over time may be poor. Understanding the reasons for poor treatment adherence and persistence in patients with AD is crucial for determining effective strategies to address and improve outcomes of this problem.

\section{Determinants of Non-Adherence in AD}

As treatment adherence is presently suboptimal in $\mathrm{AD}$, the potential benefits of the available effective therapies are not being fully experienced, either by patients or caregivers [8]. Non-adherence to treatment can either occur as the result of a considered deliberate decision (intentional non-adherence) or can happen unintentionally (unintentional nonadherence) due to misunderstanding instructions, forgetfulness or unforeseen circumstances. Furthermore, within these categories, patient, caregiver and prescriber factors all exert influences on medication adherence (fig. 2) [1].

\section{Intentional Non-Adherence}

Intentional non-adherence is based on patient, caregiver or prescriber beliefs and perceptions about the illness and the treatments available for it. It is clear from the literature that few studies have investigated illness perceptions specifically in dementia or $\mathrm{AD}$, and none have specifically investigated the impact of illness perceptions on treatment adherence [34-36].

Patient Beliefs

Patient understanding and beliefs about their illness may impact on their likelihood both to seek help for their symptoms and also to adhere to any recommended therapies. A review of qualitative research proposed that three phases of decision making are important regarding medication adherence in older people: faith in the prescriber's ability to correctly diagnose and select treatment; testing of the effectiveness of the medication on symptom relief and adverse effects, and patients' beliefs about the illness itself [37]. Any one of these can influence attitudes to treatment and adherence. For example, in one study, patients with mild-tomoderate AD did not perceive themselves as being ill and assessed their condition as stable or improving [35]; such misconceptions may alter a patient's acceptance for taking medications. As such, there is clearly a need to educate patients both about the disease itself and available treatment options. 


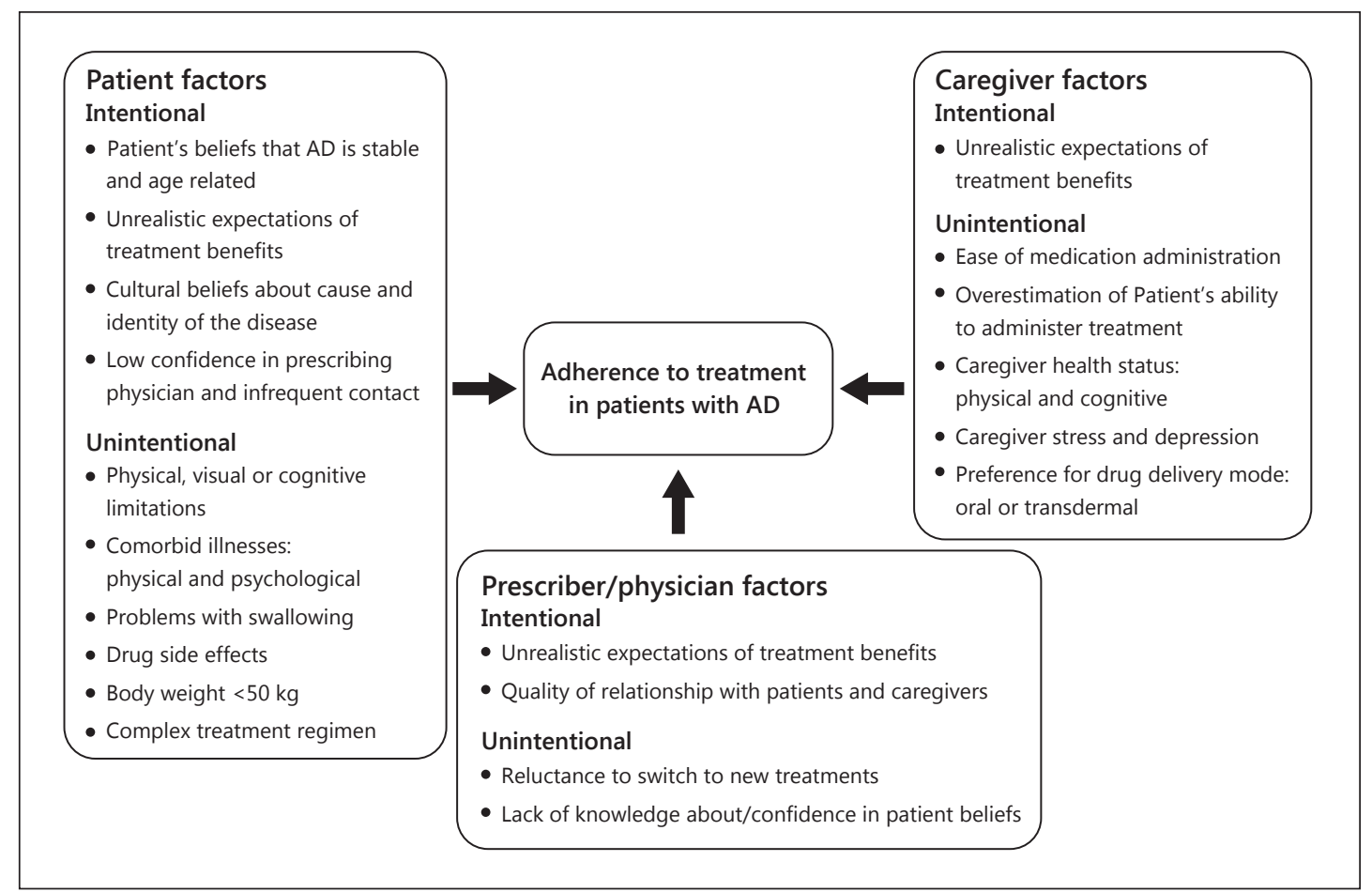

Fig. 2. Possible predictors for treatment non-adherence in patients with AD.

Along with beliefs about the disease itself, there is an expectation among patients with $\mathrm{AD}$ (along with their caregivers) for symptom improvement following treatment, and disease stabilisation is not necessarily valued. This may discourage persistence with any medications, such as ChEIs, that treat only the symptoms of disease [5, 8].

Caregiver Beliefs

Cultural beliefs may also impact on treatment decisions [38, 39]. One study showed that Hispanic and Chinese caregivers were more likely than caregivers from other cultural groups to believe that $\mathrm{AD}$ is part of the normal ageing process - such attitudes may delay help seeking by these caregivers, the patients and other family members [39].

Another study specific to AD assessed the attitudes of first-degree relatives (not necessarily caregivers) towards future availability of suitable treatments for the symptoms of AD [36]. The results suggested a positive attitude to AD pharmacological treatments in general. As ChEIs cannot reverse the disease, it is very important that caregiver expectations of treatment outcome are realistic. Indeed, a large perception difference has been reported between physicians and caregivers of patients with AD regarding many aspects of care (including disease aetiology, pathogenesis, dosage and treatment recommendations and adherence) [40]. This highlights the need to improve the communication process between prescribers and caregivers in order to optimise clinical management of AD, which may include increased adherence to effective therapies [40]. Furthermore, in a recent study, overall caregiver satisfaction with treatment for AD did not correlate with patient compliance to treatment, but it did correlate with the changes in patient's cognitive impairment, a factor that also influences caregiver's burden [14]. It therefore follows that improvements in adherence to ChEIs would have a positive impact on caregiver burden. 
Prescriber Beliefs

In addition to patient and caregiver attitudes, the attitudes and beliefs of prescribing physicians are also likely to impact on treatment adherence and persistence in AD. Massoud et al. [41] suggested that physicians may not persist with AD treatments because they do not regard stabilisation of the disease as a great benefit. However, as discussed previously, in a condition such as $\mathrm{AD}$, where there is a steady deterioration in a patient's cognitive and functional abilities, treatments that stabilise symptoms or delay progression, even for 6-12 months, can have important benefits on QoL for both patients and their caregivers $[8,14,15]$. Physician education on the value of disease stabilisation and symptom relief, to both patients and caregivers, may therefore help to relieve caregiver burden.

\section{Unintentional Non-Adherence}

The chronic nature of AD and the associated deficits in cognitive and physical functions make patients particularly susceptible to treatment non-adherence [8]. Other factors involved in unintentional non-adherence include those related to the medication itself, as well as caregiver and prescriber factors.

\section{Patient Factors}

In the early stages of $\mathrm{AD}$, patients are involved in the management of their own medications [42]. However, as people age and the disease progresses, they have increasing physical, visual and cognitive limitations that relate directly to their ability to follow medication regimens; unfortunately, many patients do not realise the extent of these problems, considering themselves able to take their own medicines even when they are unable [43]. Numerous limitations associated with progressive $\mathrm{AD}$, including memory problems, polypharmacy, and physical problems, such as reading labels and swallowing difficulties, are all likely to have an impact on treatment adherence in $\mathrm{AD}[44,45]$. Additionally, many patients with $\mathrm{AD}$ also require medications for comorbid conditions, resulting in complex treatment regimens that are also known to decrease adherence [46].

In addition to physical limitations, the patient's tolerability of any given agent may also affect adherence, with decreased adherence likely to result from poor drug tolerability [47]. The most common adverse events associated with all three of the oral ChEIs are gastrointestinal side effects [47]. The development of novel pharmacological treatments or applications for AD may improve drug tolerability. For example, it is reported that the risk for gastrointestinal adverse events is lower with transdermal rivastigmine than with the oral formulation [48].

\section{Caregiver Factors}

Family caregivers play a role in medication management from an early onset of AD [42]. However, older caregivers are themselves likely to be affected by a range of adherence factors common in the elderly population, such as polypharmacy, comorbid conditions and declining physical and visual abilities. As a result, elderly caregivers often experience difficulties with scheduling, administration and safety issues [8]. Indeed, one study reports that $12 \%$ of caregivers were estimated to have dementia themselves, with $20 \%$ treated for psychiatric conditions such as depression, a condition which is known to affect adherence to medication $[8,49]$. Caregiver underestimation of patients' cognitive impairments and overestimation of their ability to correctly administer their own medications, particularly in the early stages of disease, are also likely to impact on adherence [42]. Furthermore, given the burden and limitations faced by many caregivers, their personal preferences for dosing schedule and route of medication administration also have the potential to inadvertently impact on treatment adherence. As such, treatment schedules, such as once-daily dosing, and 
delivery routes that allow ease of administration are likely to be seen as advantageous. For example, $>70 \%$ of caregivers have reported a preference for transdermal over oral delivery of rivastigmine [50-52].

Prescriber Factors

Prescriber factors that impact on unintentional treatment adherence in AD may include their compliance with published medical guidelines. Such adherence to medical guidelines is known to vary from country to country. For example, in the UK, uptake of new medications is slower than in many other countries; this is possibly owing to concerns about drug efficacy and safety [53]. Thus, new medications associated with better adherence may not be made available to all patients.

The frequency and quality of contact between the prescriber and the patient/caregiver are also major determinants of medication adherence, with good communication and frequent visits between patient and physician as a major factor for good adherence $[8,40]$.

\section{Interventions to Improve Adherence in AD}

To date, strategies developed to increase treatment adherence in AD have focused on new drug delivery methods [54]. Concepts suggested include extended release, orally disintegrating or sublingual tablet formulations, intranasal or short- and long-acting intramuscular or transdermal forms, and nanotechnology-based delivery systems [54]. Of these, both extended-release tablets (galantamine) and transdermal application (rivastigmine) are already available. Donepezil is also available in a once-daily dosing formulation. Transdermal patch administration of rivastigmine has been shown to be of particular benefit compared with rivastigmine capsules because of increased tolerance, smooth and consistent drug delivery, easier access to optimal dose through simple titration steps, and the potential for improved efficacy at lower doses with this mode of administration [48, 52, 55, 56]. It will be of interest to investigate how these strategies impact on patient and caregiver behaviour in the future.

Video home monitoring and reminder systems have also been tested as a means for improving compliance in cognitively impaired patients $[57,58]$. For example, in a cohort of 8 patients with mild dementia, those monitored using 2-way video technology demonstrated stable treatment adherence, whilst adherence in unmonitored patients decreased significantly over the treatment period [57]. However, these systems can be expensive and impractical to install and manage. Automated reminder devices may be easier to apply to the growing population of patients with $\mathrm{AD}$, but do not have the benefit of increasing human contact with the patient [59].

Additional strategies to improve adherence to treatment in AD need to be developed and validated. These should focus on the specific patient, caregiver and prescriber factors that have been highlighted previously (table 2). We suggest that, in addition to the development of pharmacological strategies, interventions should also include education of physicians, patients and caregivers in order to address any unrealistic beliefs and expectations around the course of disease and benefits of any treatments. Particular emphasis should also be made to any cultural beliefs about $\mathrm{AD}$, whilst the importance of treatment adherence should be stressed to both patient and caregiver. Good communication and frequent contact between patient, caregiver and physician is also of importance for all aspects of disease management. 
Table 2. Potential strategies to increase adherence to treatment in $\mathrm{AD}$

Education of patient and caregiver

Address unrealistic beliefs and expectations concerning disease progression and treatment benefits

Describe the benefits of treatment adherence

Discuss cultural beliefs

Improved communication between prescriber and patient/caregiver

Frequent contact

Prescriber understanding of patient beliefs

Pharmacological properties of medications

Simplified treatment regimens

Enhanced mode of administration

Improved tolerability profile

\section{Conclusions}

By delaying the progression of AD symptoms, even for a few months, ChEIs can improve QoL for patients with AD and their caregivers. However, in order to achieve maximum benefit from these agents, as with any other medication, it is important that medication schedules are fully adhered to.

Important determinants of adherence to treatments in patients with AD include patient, caregiver and prescriber factors. Along with the physical, cognitive and psychological characteristics of caregivers and patients, their beliefs about AD and expectations about the efficacy of treatment may also be key determinants of adherence and should be addressed in any interventions aimed at improving it. The pharmacological development of ChEIs in order to improve treatment adherence, efficacy and tolerability has been reported in the literature. Consequently, a number of studies have reported on the benefits of transdermal drug delivery of rivastigmine in patients with AD. Further research is required to determine the extent to which such interventions improve adherence in this patient population.

\section{Acknowledgements}

R.B. is an employee of Atlantis Healthcare, and J.W. is a consultant for Atlantis Healthcare. Atlantis Healthcare was commissioned by Novartis to develop a carer support programme for patients prescribed the rivastigmine patch. Editorial assistance was provided by Fishawack Communications; this was funded by Novartis Pharma AG.

\section{References}

1 The National Collaborating Centre for Primary Care (2009) Medicines adherence: Involving patients in decisions about prescribed medicines and supporting adherence. http://www.nice.org.uk/nicemedia/live/ 11766/42971/42971.pdf (accessed December 15, 2011).

2 Haynes RB, Ackloo E, Sahota N, McDonald HP, Yao X: Interventions for enhancing medication adherence. Cochrane Database Syst Rev 2008;CD000011.

3 Reitz C, Brayne C, Mayeux R: Epidemiology of Alzheimer disease. Nat Rev Neurol 2011;7:137-152.

- 4 Ballard C, Gauthier S, Corbett A, Brayne C, Aarsland D, Jones E: Alzheimer's disease. Lancet 2011;377:10191031.

5 Massoud F, Gauthier S: Update on the pharmacological treatment of Alzheimer's disease. Curr Neuropharmacol 2010;8:69-80. 
- 6 Farlow MR, Miller ML, Pejovic V: Treatment options in Alzheimer's disease: maximizing benefit, managing expectations. Dement Geriatr Cogn Disord 2008;25:408-422.

7 Birks J: Cholinesterase inhibitors for Alzheimer's disease. Cochrane Database Syst Rev 2009;CD005593.

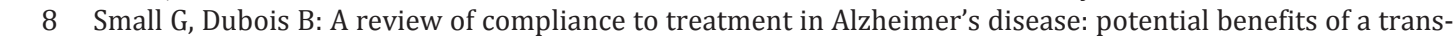
dermal patch. Curr Med Res Opin 2007;23:2705-2713.

- 9 Lyle S, Grizzell M, Willmott S, Benbow S, Clark M, Jolley D: Treatment of a whole population sample of Alzheimer's disease with donepezil over a 4-year period: lessons learned. Dement Geriatr Cogn Disord 2008; 25:226-231.

10 Birks J, Harvey RJ: Donepezil for dementia due to Alzheimer's disease. Cochrane Database Syst Rev 2006; CD001190.

11 Birks J, Grimley Evans J, Iakovidou V, Tsolaki M, Holt FE: Rivastigmine for Alzheimer's disease. Cochrane Database Syst Rev 2009;CD001191.

12 Loy C, Schneider L: Galantamine for Alzheimer's disease and mild cognitive impairment. Cochrane Database Syst Rev 2006;CD001747.

13 Grossberg GT: Impact of rivastigmine on caregiver burden associated with Alzheimer's disease in both informal care and nursing home settings. Drugs Aging 2008;25:573-584.

14 Molinuevo JL, Hernandez B: Profile of the informal carer associated with the clinical management of the Alzheimer's disease patient refractory to symptomatic treatment of the disease. Neurologia 2011;26:518527.

15 Howe E: Improving the quality of life in patients with Alzheimer's disease. Psychiatry (Edgmont) 2008;5: 51-56.

16 Beinart N, Weinman J, Wade D, Brady R: Caregiver burden and psychoeducational interventions in Alzheimer's disease: a review. Dement Geriatr Cogn Disord Extra 2012;2:638-648.

$\checkmark 17$ Helzner EP, Scarmeas N, Cosentino S, Tang MX, Schupf N, Stern Y: Survival in Alzheimer disease: a multiethnic, population-based study of incident cases. Neurology 2008;71:1489-1495.

18 Gillette-Guyonnet S, Andrieu S, Cortes F, Nourhashemi F, Cantet C, Ousset PJ, Reynish E, Grandjean H, Vellas B: Outcome of Alzheimer's disease: potential impact of cholinesterase inhibitors. J Gerontol A Biol Sci Med Sci 2006;61:516-520.

19 Wolstenholme J, Fenn P, Gray A, Keene J, Jacoby R, Hope T: Estimating the relationship between disease progression and cost of care in dementia. Br J Psychiatry 2002;181:36-42.

20 Hill J, Fillit H, Thomas SK, Chang S: Functional impairment, healthcare costs and the prevalence of institutionalisation in patients with Alzheimer's disease and other dementias. Pharmacoeconomics 2006;24:265-280.

-21 Borah B, Sacco P, Zarotsky V: Predictors of adherence among Alzheimer's disease patients receiving oral therapy. Curr Med Res Opin 2010;26:1957-1965.

22 Amuah JE, Hogan DB, Eliasziw M, Supina A, Beck P, Downey W, Maxwell CJ: Persistence with cholinesterase inhibitor therapy in a population-based cohort of patients with Alzheimer's disease. Pharmacoepidemiol Drug Saf 2010;19:670-679.

-23 Blais L, Kettani FZ, Perreault S, Leroux JC, Forget A, Kergoat MJ: Adherence to cholinesterase inhibitors in patients with Alzheimer's disease. J Am Geriatr Soc 2009;57:366-368.

24 Gadzhanova S, Roughead L, Mackson J: Anticholinesterase duration in the Australian veteran population. Aust NZ J Psychiatry 2010;44:469-474.

25 Herrmann N, Binder C, Dalziel W, Smyth S, Camacho F: Persistence with cholinesterase inhibitor therapy for dementia: an observational administrative health database study. Drugs Aging 2009;26:403-407.

26 Kroger E, van Marum R, Souverein P, Egberts T: Discontinuation of cholinesterase inhibitor treatment and determinants thereof in the Netherlands: a retrospective cohort study. Drugs Aging 2010;27:663-675.

27 Massoud F, Dorais M, Charbonneau C, Lescrauwaet B, Boucher JM, LeLorier J: Drug utilization review of cholinesterase inhibitors in Quebec. Can J Neurol Sci 2008;35:508-509.

28 Mucha L, Shaohung S, Cuffel B, McRae T, Mark TL, Del Valle M: Comparison of cholinesterase inhibitor utilization patterns and associated health care costs in Alzheimer's disease. J Manag Care Pharm 2008;14:451461.

29 Pariente A, Pinet M, Moride Y, Merliere Y, Moore N, Fourrier-Reglat A: Factors associated with persistence of cholinesterase inhibitor treatments in the elderly. Pharmacoepidemiol Drug Saf 2010;19:680-686.

-30 Roe CM, Anderson MJ, Spivack B: How many patients complete an adequate trial of donepezil? Alzheimer Dis Assoc Disord 2002;16:49-51.

31 Singh G, Thomas SK, Arcona S, Lingala V, Mithal A: Treatment persistency with rivastigmine and donepezil in a large state medicaid program. J Am Geriatr Soc 2005;53:1269-1270.

-32 Suh DC, Thomas SK, Valiyeva E, Arcona S, Vo L: Drug persistency of two cholinesterase inhibitors: rivastigmine versus donepezil in elderly patients with Alzheimer's disease. Drugs Aging 2005;22:695-707.

33 Schwalbe 0, Scheerans C, Freiberg I, Schmidt-Pokrzywniak A, Stang A, Kloft C: Compliance assessment of ambulatory Alzheimer patients to aid therapeutic decisions by healthcare professionals. BMC Health Serv Res 2010;10:232.

34 Harman G, Clare L: Illness representations and lived experience in early-stage dementia. Qual Health Res 2006;16:484-502.

35 Clare L, Goater T, Woods B: Illness representations in early-stage dementia: a preliminary investigation. Int J Geriatr Psychiatry 2006;21:761-767. 
36 Roberts JS, Connell CM: Illness representations among first-degree relatives of people with Alzheimer disease. Alzheimer Dis Assoc Disord 2000;14:129-136; discussion 127-128.

37 Banning M: Older people and adherence with medication: a review of the literature. Int J Nurs Stud 2008;45: 1550-1561.

38 Mukadam N, Cooper C, Livingston G: A systematic review of ethnicity and pathways to care in dementia. Int J Geriatr Psychiatry 2011;26:12-20.

-39 Gray HL, Jimenez DE, Cucciare MA, Tong HQ, Gallagher-Thompson D: Ethnic differences in beliefs regarding Alzheimer disease among dementia family caregivers. Am J Geriatr Psychiatry 2009;17:925-933.

$\checkmark 40$ Molinuevo JL, Hernandez B: Assessment of the information provided by the medical specialist on Alzheimer's disease and that retained by the patient caregivers. Neurologia 2012;27:453-471.

41 Massoud F, Belleville S, Bergman H, Kirk J, Chertkow H, Nasreddine Z, Joanette Y, Freedman M: Mild cognitive impairment and cognitive impairment, no dementia: part B, therapy. Alzheimers Dement 2007;3:283-291.

42 Cotrell V, Wild K, Bader T: Medication management and adherence among cognitively impaired older adults. J Gerontol Soc Work 2006;47:31-46.

43 Beckman AG, Parker MG, Thorslund M: Can elderly people take their medicine? Patient Educ Couns 2005;59: 186-191.

-44 Kairuz T, Bye L, Birdsall R, Deng T, Man L, Ross A, Samarasinha I, Tautolo E: Identifying compliance issues with prescription medicines among older people: a pilot study. Drugs Aging 2008;25:153-162.

$\$ 45$ Tordoff JM, Bagge ML, Gray AR, Campbell AJ, Norris PT: Medicine-taking practices in community-dwelling people aged $>$ or $=75$ years in New Zealand. Age Ageing 2010;39:574-580.

-46 Corsonello A, Pedone C, Lattanzio F, Lucchetti M, Garasto S, Carbone C, Greco C, Fabbietti P, Incalzi RA: Regimen complexity and medication nonadherence in elderly patients. Ther Clin Risk Manag 2009;5:209-216.

47 Bassil N, Grossberg GT: Novel regimens and delivery systems in the pharmacological treatment of Alzheimer's disease. CNS Drugs 2009;23:293-307.

48 Darreh-Shori T, Jelic V: Safety and tolerability of transdermal and oral rivastigmine in Alzheimer's disease and Parkinson's disease dementia. Expert Opin Drug Saf 2010;9:167-176.

49 Riepe MW, Ibach B: Neurological and psychiatric practitioners' views on Alzheimer's disease and treatment thereof. Dement Geriatr Cogn Disord 2008;26:541-546.

50 Abetz L, Rofail D, Mertzanis P, Heelis R, Rosa K, Tellefsen C, Roborel de Climens A, McBurney C, Thomas S: Alzheimer's disease treatment: assessing caregiver preferences for mode of treatment delivery. Adv Ther 2009;26:627-644.

-51 Blesa R, Ballard C, Orgogozo JM, Lane R, Thomas SK: Caregiver preference for rivastigmine patches versus capsules for the treatment of Alzheimer disease. Neurology 2007;69:S23-S28.

52 Winblad B, Kawata AK, Beusterien KM, Thomas SK, Wimo A, Lane R, Fillit H, Blesa R: Caregiver preference for rivastigmine patch relative to capsules for treatment of probable Alzheimer's disease. Int J Geriatr Psychiatry 2007;22:485-491.

53 Mason A: New medicines in primary care: a review of influences on general practitioner prescribing. J Clin Pharm Ther 2008;33:1-10.

54 Di Stefano A, Iannitelli A, Laserra S, Sozio P: Drug delivery strategies for Alzheimer's disease treatment. Expert Opin Drug Deliv 2011;8:581-603.

55 Chan AL, Chien YW, Jin Lin S: Transdermal delivery of treatment for Alzheimer's disease: development, clinical performance and future prospects. Drugs Aging 2008;25:761-775.

56 Dhillon S: Rivastigmine transdermal patch: a review of its use in the management of dementia of the Alzheimer's type. Drugs 2011;71:1209-1231.

57 Smith GE, Lunde AM, Hathaway JC, Vickers KS: Telehealth home monitoring of solitary persons with mild dementia. Am J Alzheimers Dis Other Demen 2007;22:20-26.

58 O’Neill SA, Parente G, Donnelly MP, Nugent CD, Beattie MP, McClean SI, Scotney BW, Mason SC, Craig D: Assessing task compliance following mobile phone-based video reminders. Conf Proc IEEE Eng Med Biol Soc 2011;2011:5295-5298.

59 Kamimura T, Ishiwata R, Inoue T: Medication reminder device for the elderly patients with mild cognitive impairment. Am J Alzheimers Dis Other Demen 2012;27:238-242.

60 Gardette V, Andrieu S, Lapeyre-Mestre M, Coley N, Cantet C, Ousset PJ, Grand A, Monstastruc JL, Vellas B: Predictive factors of discontinuation and switch of cholinesterase inhibitors in community-dwelling patients with Alzheimer's disease: a 2-year prospective, multicentre, cohort study. CNS Drugs 2010;24:431-442. 